\title{
Influence of noise manipulation on retention in a simulated ICU ward round: an experimental pilot study
}

\author{
Katja Erne ${ }^{1 \dagger}$, Samuel E. J. Knobel ${ }^{1 \dagger}$, Aileen C. Naef ${ }^{1}$, Stephan M. Gerber ${ }^{1}$, Tim Fischer ${ }^{4}$, Fred W. Mast ${ }^{3}$, \\ Joerg C. Schefold ${ }^{2}$, Bjoern Zante ${ }^{2}$, Tobias Nef ${ }^{1,4,5^{*+}}$ (ID and Marie-Madlen Jeitziner ${ }^{2,6+}$
}

\begin{abstract}
*Correspondence:
tobias.nef@artorg.unibe.ch

${ }^{\dagger}$ Katja Erne and Samuel E. J.

Knobel shared first authors

${ }^{\dagger}$ Tobias Nef and Marie-

Madlen Jeitziner shared last

authors

${ }^{1}$ Gerontechnology

and Rehabilitation

Group, University of Bern,

Murtenstrasse 50, 3008 Bern,

Switzerland

Full list of author information

is available at the end of the

article
\end{abstract}

\begin{abstract}
Background: Noise exposure leads to a reduction in cognitive abilities in diverse settings, however, only limited data exist examining the effects of environmental ICU noise on the cognitive performance of ICU professionals. A frequently occurring and demanding retention task in ICUs are ward rounds, which are considered key for the provision of medical care. Here, we investigate the influence of noise on information retention in a simulated ward round.
\end{abstract}

Methods: ICU professionals were exposed to a recorded, ICU ward round, simulated partly with and partly without environmental ICU noise. Ward rounds were followed by specific questions about previously provided information.

Results: 56 ICU professionals (aged 26-59 years) were included. A logistic mixed model showed a reduction of $27 \%(P<0.001)$ in the ward round test performance when participants were exposed to environmental ICU noise. Furthermore, advanced age was associated with reduced retention $(-28 \%, P<0.001)$, questions containing important information performed better $(+36 \%, P<0.001)$, and higher stress led to better performance in retention $(+24 \%, P=0.01)$.

Conclusions: Our data showed a considerable negative influence of environmental ICU noise during a simulated ward round. Therefore, reduction of environmental ICU noise is recommended. The influence of additional factors, including stress, priorities, and demographic factors should be pursued in subsequent investigations.

Keywords: Intensive Care Unit, Noise, Ward round, Retention, Pilot study

\section{Background}

Intensive Care Unit (ICU) professionals are exposed to a lot of noise in their ICU work environment [1,2]. This raises concerns as noise has been found to have a negative impact on cognitive performance in other occupational settings [3]. However, at this time, there is a lack of knowledge about the impact of increased noise exposure on the work performance of ICU professionals.

In the ICU, examples of the most common sound sources are equipment (e.g. monitor or ventilator alarms), patient care (e.g. patient transfer), patients themselves (e.g. author(s) and the source, provide a link to the Creative Commons licence, and indicate if changes were made. The images or other third party material in this article are included in the article's Creative Commons licence, unless indicated otherwise in a credit line to the material. If material is not included in the article's Creative Commons licence and your intended use is not permitted by statutory regulation or exceeds the permitted use, you will need to obtain permission directly from the copyright holder. To view a copy of this licence, visit http:// creativecommons.org/licenses/by/4.0/. 
coughing), the immediate work environment (e.g. staff conversations), and general background noise [1]. When combined, ICU sound levels can reach average decibel levels as high as $70 \mathrm{dBA}(66+6.1 \mathrm{dBA})$ [4]. However, the sound levels within the ICU can vary over time [4], for example depending on proximity to the patient or with the occurrence of group discussions [5]. Specific to the ICU, and in the context of this study, the sound environment (i.e. patient alarms, coughing, yelling, preparing medication, and equipment sounds), is defined as noise when there is a negative perception associated to it [6, 7]. This is the case for ICU professionals, as they perceive the aforementioned sounds in their environment as being negative [2]. Heightened noise levels in ICUs have subjectively been found to induce annoyance and stress, decrease overall well-being, and reduce work performance [2]. However, as noise is subjective it may in certain circumstances not be perceived negatively, for example for some people the phone ringing may be associated with a positive reaction or memory.

The impact of background noise in a non-hospital setting has been widely discussed in the literature and reduced performance in cognitive functions has been shown, such as in working memory [8], recall [9], and attention [3]. Additionally, further factors, such as work experience $[10,11]$, stress [12, 13], age [14], and motivation [10] may also influence cognitive functions or work performance. Specifically, in the hospital setting, limited studies have investigated the noise effect on cognitive performance. One study by Murthy et al., that did look at this, found that medical professionals had lower performance on short-term memory and mental efficiency when exposed to operating room background noise [15]. Furthermore, higher error rates were shown in an anaesthesiology setting when exposed to environmental noise [16]. As the presence of environmental noise distracts medical professionals, especially during cognitively demanding tasks [17], they might be particularly affected by environmental ICU noise.

The effect of noise could be especially important during ICU ward rounds, which are used to communicate between shifts [18]. Ward rounds are known to be cognitively demanding as they contain complex content [19] and have the potential to directly impact ICU care [20]. Specifically, ward rounds involve multiple individuals gathering around the patient bed to share information amongst themselves. This differs from standard patient care around the bed, like delivering medication to the patient, which is usually done by a single nurse. We, therefore, embarked to investigate the influence of environmental ICU noise on the retention ability of ICU professionals in a simulated ICU ward round. Other influencing variables, such as age, stress, and motivation were also analysed.

\section{Methods}

The aim of the simulated ward round was to assess the influence of ICU noise on the retention ability of ICU professionals, in an experimental setting. Potential influencing variables were also included for a more precise influence analysis of the retention ability after ward rounds.

\section{Participants}

Participants were ICU professionals, namely nurses and physicians, working in the Department of Intensive Care Medicine at the University Hospital Bern in Switzerland. 
They were invited via word-of-mouth during their working shift. Professionals were excluded if any of the following criteria were met, age under 18 years, pre-existing known neurological disorder or auditory impairment, or use of prescribed medication that could alter the level of alertness. Participation was voluntary and all participants signed a written informed consent. The study was approved by the local ethics committee at the University of Bern (No.: 2020-04-00,009). The study was performed in adherence to the Declaration of Helsinki.

\section{Procedure}

This pilot study took place in a quiet room in the hospital, where a maximum of two ICU professionals could participate at a time. When there was more than one participant at a time, they sat with their backs to each other while wearing noise-cancelling over-ear headphones. Each participant listened to eight different audio files (i.e. eight patient cases presented in a single ICU ward round, for detailed content see Additional file 1: S3 and for more audio details see section Audio Files) in a randomised order. Participants were instructed to memorise the content of the ward round as they would during reallife ward rounds. Participants were allowed to take written notes of any information, as if in real-life ward rounds.

All the cases presented in the ward round had two versions, one version included only the speech of the ward round, and the second version included simulated ICU noise in addition to the speech (Speech Condition vs. Noise Condition). The participants then listened to half of the cases in the Speech Condition and the other half in the Noise Condition. The starting condition and the order in which the eight patient cases were presented to the participants were randomised, while the conditions (i.e. Speech Condition vs Noise Condition) were presented alternately. Directly after listening to the eight audio files, participants' demographics were collected, and the ward round test (for details see section Questionnaires and Additional file 1: S3), noise sensitivity, and individual variables (e.g. motivation, concentration) were assessed via questionnaires (Additional file 1: S2 and S3).

\section{Audio files}

Each audio file contained a simulated ICU ward round case, designed and recorded by an ICU physician (Additional file 1: S1). Audio files consisted of 301-385 words $(M=341.4, \mathrm{SD}=27.6)$ and were played at a weighted sound pressure level of $70 \mathrm{~dB}$ SPL. In the Noise Condition simulated ICU noise was added. The simulated noise was manually constructed by adding different ICU sound sources, such as alarms and pagers, to ICU background noise recorded in a real ICU environment. Due to the limited effect of alarms on overall sound levels [21], the audio files are based mainly on unintelligible background conversations. The frequency range of simulated noise files were between $50 \mathrm{~Hz}$ and $22 \mathrm{kHz}$, with peaks between 2.2 and $3.4 \mathrm{kHz}$ that resulted from the pagers. Each simulated noise file contained six peaks. The noise was played with a signal-tonoise ratio of $-5 \mathrm{~dB}$ SPL so that the speaking voice could be understood in all cases (Additional file 1: S4). 


\section{Questionnaires}

A self-constructed test of each ward round was assessed using an eight-item free recall questionnaire (Ward round test, Additional file 1: S3). During the creation of the test, two ICU professionals rated the importance of each question (" 1 not important" to " 5 very important") and all questions with a mean rating below 3 were replaced by new questions with higher ratings of importance. The final questions at the end, therefore, included only questions rated as important (rating mean $\geq 3$ ), such as current medication, Glasgow Coma Score, reason for being at the ICU, and the state of affairs with the relatives.

Additionally, the Weinstein Noise Sensitivity-Scale (WNS) [22] which applies a six-point Likert scale (1 "strongly disagree" to 6 "strongly agree"), to rate the individual noise sensitivity in different noise situations was used. Questions looking at the individual participant variables (e.g. concentration, motivation) were based on selfreports of the participants, they included direct questions such as "How motivated were you to perform well during the study?" with an answer scale of 0 "very low" to 100 "very high" (for full list of participant variables see Additional file 1: S2).

\section{Statistical analysis}

Sample size and statistical power was investigated using Monte Carlo simulations. Five ICU experts tried the ward round test, based on these results, we assumed that if noise was present (Noise Condition) a correct response rate of $50 \%$ would be obtained. An improvement of $10 \%$ was assumed to be clinically relevant [23]. With these assumptions, a sample size of 50 subjects and an alpha of $5 \%$ would provide a statistical power of $89 \%$.

The effect of the Noise versus Speech Conditions in the audio files on the probability of a correct answer was calculated using a logistic mixed model with the controlled random effects of the participant number, patient, and question number. The influencing factors included presence of ICU noise, age, importance of question, stress, monthly working hours, working hours before study participation, noise sensitivity, subjective hearing performance, concentration, concentration in noise environments, energy, motivation, and notes habit. These factors were included as fixed factors in the model calculation.

Fisher's exact test was used to assess if the distribution of the cases (how many times a case was answered in a certain condition) was significantly different from a random distribution [24]. All calculations were made using the statistical program R-Studio [25].

\section{Results}

A total of 56 ICU professionals ( $n=12$ physicians, $n=44$ nursing professionals) participated in the study between May and June 2020. Mean age was $38.4 \pm 8.40$ years [26; 59] and 17 were male, 38 were female, and 1 was not specified (Table 1 ).

\section{Correct answers per case}

Descriptive analyses showed the percentage of the correct responses given in the ward round test per case. Percent correct answers in the ward round test showed higher 
Table 1 Participant demographics

\begin{tabular}{ll}
\hline Detailed demographics & \\
\hline Characteristic & Value \\
\hline Work experience as ICU professional, years & $9.28 \pm 8.46,[0.17 ; 36]$ \\
Participants working before participating in the study & $40(71.4 \%)$ \\
Mean working time before study participation, hours & $4.79 \pm 2.29,[1 ; 9]$ \\
Preferred working environment & $46(82.1 \%)$ \\
- Quiet environment & $8(14.3 \%)$ \\
- No preference & $2(3.6 \%)$ \\
- Noisy environment & \\
Subjective hearing performance & $60.7 \pm 17.0$ \\
0"very bad"to 100 "very good" & \\
\hline
\end{tabular}

Information was collected after listening to the ward rounds but prior to retention testing (ward round test), mean $\pm S D$ [min; max], or number of participants $n(\%)$ are given

Table 2 Percent correct answers in the ward round test

\begin{tabular}{lll}
\hline Case & Noise condition [\%] & Speech condition [\%] \\
\hline 1 & $52(n=33)$ & $58(n=23)$ \\
2 & $54(n=27)$ & $70(n=29)$ \\
3 & $52(n=28)$ & $56(n=28)$ \\
4 & $69(n=29)$ & $68(n=27)$ \\
5 & $57(n=24)$ & $69(n=32)$ \\
6 & $61(n=32)$ & $59(n=24)$ \\
7 & $57(n=23)$ & $70(n=33)$ \\
8 & $55(n=28)$ & $60(n=28)$ \\
\hline
\end{tabular}

Displays correct answers given by the participants $(\mathrm{n})$ per condition and case

retention performance in the Speech Condition in six of the eight patient cases presented during the ward round (Table 2). Due to the randomisation of the order of the cases, the two conditions came up with different frequencies. Nevertheless, according to Fisher's exact test for data count there was no case-condition that was significantly more or less frequent than others $(P=0.55)$.

\section{Noise-effect on influencing variables}

In the mixed logistic regression analysis, the Noise Condition led to a decrease of $27 \%$ $(P<0.001$, Table 3$)$ in the ward round test performance. Moreover, a negative effect for higher age was observed $(-28 \%, P<0.001)$, more important questions performed better $(+36 \%, P<0.001)$, and higher perceived stress in the past week led to better performance in the ward round test $(+24 \%, P=0.01)$.

\section{Discussion}

Our study showed a considerable decline in performance in the ICU ward round test when background noise was present. Moreover, with advanced age the participants showed more errors in the ward round test, and ward round test questions rated as more important were answered correctly more often. Lastly, more stressed participants had higher test results in the ward round test. The self-perceived noise sensitivity seemed not to affect the ICU ward round test performance. 
Table 3 Complete performance estimate-based influencing factors

\begin{tabular}{lllll}
\hline & Odds ratio & $\mathbf{9 5 \%} \mathbf{C l}$ & $\boldsymbol{z}$ value & $\boldsymbol{P}$ value \\
\hline Noise & 0.73 & $0.63-0.84$ & -4.31 & 0.00 \\
Age & 0.72 & $0.61-0.85$ & -3.99 & 0.00 \\
Importance of question & 1.36 & $1.26-1.46$ & 7.80 & 0.00 \\
Stress & 1.24 & $1.04-1.47$ & 2.47 & 0.01 \\
Monthly working hours & 0.99 & $0.82-1.19$ & -0.12 & 0.91 \\
Working hours before study participation & 0.88 & $0.76-1.03$ & -1.57 & 0.12 \\
Noise sensitivity (WNS) & 0.90 & $0.75-1.08$ & -1.10 & 0.27 \\
Subjective hearing performance & 0.95 & $0.82-1.11$ & -0.62 & 0.54 \\
Concentration & 0.88 & $0.72-1.09$ & -1.16 & 0.25 \\
Concentration in noise environments & 1.00 & $0.82-1.21$ & -0.05 & 0.96 \\
Energy & 0.99 & $0.83-1.15$ & -0.06 & 0.95 \\
Motivation & 0.97 & $0.83-1.15$ & -0.32 & 0.75 \\
Taking notes as in real ward rounds & 0.77 & $0.57-1.05$ & -1.63 & 0.10 \\
\hline
\end{tabular}

WNS Weinstein noise sensitivity-scale

The ICU professionals in this study showed a $27 \%$ reduction in retention performance in the ward round test during the Noise Condition. This is consistent with literature from outside the hospital, regarding the impact of environmental noise on memory retrieval performance $[9,26,27]$. Additionally, the result is supported by findings which show that noise leads to higher error rates and decreases mental efficiency and shortterm memory in a medical context $[15,16]$. Unfortunately, many of the past studies did not measure the performance with real daily work exercises. Therefore, we deliberately aimed to mimic a real ICU ward round, including allowing participants' to take notes. Note taking is known to have a positive effect on deeper information processing [28] and should, therefore, lead to better results in retention tests. However, as the participants performed worse in the ward round test, even if they took notes and used them to answer the task-related questions, this supports the finding that noise has a strong negative effect on retention. As the performance of medical professionals is essential for good medical care [20], noise reduction during ward rounds is recommended to increase patient safety.

Our study showed a negative effect of age on the ward round test performance. This is in line with literature which confirms that older people make more long-term selective attention and concentration errors [29]. Moreover, age-related functional brain changes may lead to a reduction of different memory functions [30-32]. Therefore, our findings regarding age are not surprising, however, other aspects, such as compensating strategies [33], or individual variables such as test anxiety [34] may be related to performance in age and were not taken into account. Another possible explanation might be the reduced capabilities of distinguishing background sounds with increasing age [35]. As hearing performance was not objectively assessed in this study, the question of agerelated performance may be an interesting topic for future investigation.

This study only included questions subjectively rated as important. However, from these questions, those with a higher score of importance were more often answered correctly by the ICU professionals. This may occur due to learning effects due to repeating test questions [36]. ICU professionals respond daily to routine questions, which they inevitably have 
to be able to answer after ward rounds during their work routine. In this way, certain questions may have been answered correctly more often due to their importance and appearance in daily, real-life, ward rounds.

Our study also showed better retention results in ICU professionals experiencing more stress in the past seven days. The effect of stress on performance remains conflicting in the literature [37]. On the one hand, an immediate stress reaction induced via glucocorticoids can enhance memory retrieval and consolidation [12], however on the other hand, studies have also found impaired memory retrieval under stress [13]. Therefore, further research is needed to understand the full effect of stress on the retrieval performance of ICU professionals.

The self-reported noise sensitivity of the participants showed no effect on the ward round test, which is not in line with most of the literature [38, 39]. A possible explanation for this discrepancy might be that ICU staff becomes less sensitive to ICU alarms over time [40], which may lead to less ICU background noise-induced distraction. Some literature, such as Ljungberg and Neely support our finding, as they found that noise sensitivity was not a relevant factor in an attention task [41]. Another reason might be that our study did not had enough power to find an effect of self-reported noise sensitivity. Therefore, the relevance of noise sensitivity of cognitive functions remains controversial and needs further investigations with studies where the sample sizes are powered to this hypothesis.

Our study had some limitations that include the monocentric study design which may limit external validity [42]. However, most hospitals do provide information and lead discussions at the ICU bed, which may be influenced by noise. Therefore, this is an organisational aspect to be considered in the structural layout of future ICUs, in order to permit ward rounds to be conducted at a distance from the patient bed. Additionally, hospitals which conduct ward rounds in this way could consider adapting how they manage the transfer of information.

Because noise is a factor which, from the hospital side, can be adjusted, this pilot study focused on the noise influence on memory retrieval of ICU professionals. However, we measured superficially other aspects (screening), which were found to be important, too. In further studies, however, a deeper focus on these aspects is necessary. Especially, the inclusion of other memory tasks might lead to complementary results.

Moreover, due to the investigatory nature of a pilot study ICU professionals were grouped in this first analysis, however, future work would need to differentiate between these two groups.

Finally, absence of real patients in the experimental setting could be a limitation. On the one hand, the presence of patients may be important, because they could support the memorisation of information as it is being received both visually and auditory [43], on the other hand, distractions during the ward round because of interaction with the patient, might also have a negative impact [44]. Therefore, the retention in real ward rounds should be investigated in future studies. 


\section{Conclusions}

Environmental noise in the ICU during ward rounds negatively influences retention of ICU professionals. Our data lend to the fact that reducing noise, e.g. by means of targeted interventions, should be investigated. Ideally these interventions will target age, stress, and the influence of important questions.

\section{Take home message}

1. Environmental ICU noise reduced retention in ICU professionals by about $27 \%$.

2. Younger age, importance of information, and stress level positively influenced the retention performance of ICU professionals.

\section{Abbreviations}

ICU: Intensive Care Unit; dBA: Decibel (A-weighted); dB SPL: Decibel sound pressure level; WNS: Weinstein Noise Sensitivity-Scale.

\section{Supplementary Information}

The online version contains supplementary material available at https://doi.org/10.1186/s40635-022-00430-1.

Additional file 1. Part 1. Cases. Part 2. Full Demographic Questionnaire. Part 3. Ward round questionnaire. Part 4. Audio files.

Acknowledgements

Lukas Bütikofer, PhD, CTU Bern.

\section{Authors' contributions}

KE, SEJK, ACN, SMG, BZ, TF, MMJ, JCS, FWM, SMJ, and TN were all involved in the study design, protocol development, and writing of the proposal. KE, SEJK, ACN, SMG, BZ, TF, MMJ, JCS, FWM, SMJ, and TN were all involved in writing the final manuscript. KE, SEJK, BZ, and MMJ collected and managed the data. SEJK, and KE analysed the data. KE, SEJK, ACN, and SMG interpreted the data. All authors read and approved the final manuscript.

\section{Funding}

This research did not receive any specific grant from funding agencies in the public, commercial, or not-for-profit sectors.

Availability of data and materials

The dataset used and analysed during the current study are available on reasonable request.

\section{Declarations}

Ethics approval and consent to participate

The study was carried out following the latest version of the Declaration of Helsinki and approved by the Ethics Commission of the Faculty of Human Science, University of Bern.

\section{Consent for publication}

Not applicable.

\section{Competing interests}

Full departmental disclosure: KE, BZ, JCS, and MMJ report grants from Orion Pharma, Abbott Nutrition International, B. Braun Medical AG, CSEM AG, Edwards Lifesciences Services GmbH, Kenta Biotech Ltd, Maquet Critical Care AB, Omnicare Clinical Research AG, Nestle, Pierre Fabre Pharma AG, Pfizer, Bard Medica S.A., Abbott AG, Anandic Medical Systems, Pan Gas AG Healthcare, Bracco, Hamilton Medical AG, Fresenius Kabi, Getinge Group Maquet AG, Dräger AG, Teleflex Medical GmbH, Glaxo Smith Kline, Merck Sharp and Dohme AG, Eli Lilly and Company, Baxter, Astellas, Astra Zeneca, CSL Behring, Novartis, Covidien, Hemotune, Phagenesis, Philips Medical, Prolong Pharmaceuticals, and Nycomed outside the submitted work. The money received was paid into departmental funds. No personal financial gain applied. SEJK, ACN, SMG, TF, FWM, and TN declare no conflict of interest.

\section{Author details}

${ }^{1}$ Gerontechnology and Rehabilitation Group, University of Bern, Murtenstrasse 50, 3008 Bern, Switzerland. ${ }^{2}$ Department of Intensive Care Medicine, Inselspital, Bern University Hospital, University of Bern, Bern, Switzerland. ${ }^{3}$ Department of Cognitive Psychology, Perception and Research Methods, University of Bern, Bern, Switzerland. ${ }^{4}$ ARTORG Center 
for Biomedical Engineering Research, University of Bern, Bern, Switzerland. ${ }^{5}$ Department of Neurology, Inselspital, Bern University Hospital, University of Bern, Bern, Switzerland. ${ }^{6}$ Institute of Nursing Science (INS), Department of Public Health (DPH), Faculty of Medicine, University of Basel, Basel, Switzerland.

Received: 8 October 2021 Accepted: 6 January 2022

Published online: 28 January 2022

\section{References}

1. Kam PCA, Kam AC, Thompson JF (1994) Noise pollution in the anaesthetic and intensive care environment. Anaesthesia 49:982-986. https://doi.org/10.1111/j.1365-2044.1994.tb04319.x

2. Schmidt N, Gerber SM, Zante B et al (2020) Effects of intensive care unit ambient sounds on healthcare professionals: results of an online survey and noise exposure in an experimental setting. Intensive Care Med Exp. https://doi. org/10.1186/s40635-020-00321-3

3. Golmohammadi R, Darvishi E, Faradmal J et al (2020) Attention and short-term memory during occupational noise exposure considering task difficulty. Appl Acoust. https://doi.org/10.1016/j.apacoust.2019.107065

4. Scquizzato T, Gazzato A, Landoni G, Zangrillo A (2020) Assessment of noise levels in the intensive care unit using Apple Watch. Crit Care. https://doi.org/10.1186/s13054-020-02852-3

5. Darbyshire JL, Müller-Trapet M, Cheer J et al (2019) Mapping sources of noise in an intensive care unit. Anaesthesia. https://doi.org/10.1111/anae.14690

6. Basner M, Clark C, Hansell A et al (2017) Aviation noise impacts: state of the science. Noise Health 19:41-50. https:// doi.org/10.4103/nah.NAH_104_16

7. Beutel ME, Jünger C, Klein EM et al (2016) Noise annoyance is associated with depression and anxiety in the general population- the contribution of aircraft noise. PLoS ONE 11:e0155357. https://doi.org/10.1371/journal.pone.0155357

8. Wright BAL, Peters ER, Ettinger $U$ et al (2016) Moderators of noise-induced cognitive change in healthy adults. Noise Health. https://doi.org/10.4103/1463-1741.181995

9. Hygge S, Boman E, Enmarker I (2003) The effects of road traffic noise and meaningful irrelevant speech on different memory systems. Scand J Psychol. https://doi.org/10.1111/1467-9450.00316

10. Rozi A, Sunarsi D (2020) The influence of motivation and work experience on employee performance at PT. Yamaha Saka Motor in South Tangerang. J Off 5:65. https://doi.org/10.26858/jo.v5i2.13378

11. Brewster PWH, Melrose RJ, Marquine MJ et al (2014) Life experience and demographic influences on cognitive function in older adults. Neuropsychology 28:846-858. https://doi.org/10.1037/neu0000098

12. Roozendaal B (2002) Stress and memory: opposing effects of glucocorticoids on memory consolidation and memory retrieval. Neurobiol Learn Mem 78:578-595. https://doi.org/10.1006/nlme.2002.4080

13. Kuhlmann S (2005) Impaired memory retrieval after psychosocial stress in healthy young men. J Neurosci 25:29772982. https://doi.org/10.1523/JNEUROSCl.5139-04.2005

14. Li LW, Ding D, WU B, Dong X (2017) Change of cognitive function in U.S. Chinese older adults: a population-based study. J Gerontol Ser A 72:S5-S10. https://doi.org/10.1093/gerona/glx004

15. Murthy VSSN, Malhotra SK, Bala I, Raghunathan M (1995) Detrimental effects of noise on anaesthetists. Can J Anaesth. https://doi.org/10.1007/BF03011878

16. Stevenson RA, Schlesinger JJ, Wallace MT (2013) Effects of divided attention and operating room noise on perception of pulse oximeter pitch changes. Anesthesiology 118:376-381. https://doi.org/10.1097/ALN.0b013e3182 $7 \mathrm{~d} 417 \mathrm{~b}$

17. Keller S, Tschan F, Semmer NK et al (2018) Noise in the operating room distracts members of the surgical team. An observational study. World J Surg. https://doi.org/10.1007/s00268-018-4730-7

18. Chapman KB (2009) Improving communication among nurses, patients, and physicians. Am J Nurs. https://doi.org/ 10.1097/01.NAJ.0000362013.53342.17

19. Weber H, Stöckli M, Nübling M, Langewitz WA (2007) Communication during ward rounds in internal medicine. An analysis of patient-nurse-physician interactions using RIAS. Patient Educ Couns. https://doi.org/10.1016/j.pec.2007. 04.011

20. Shankar PS (2013) Ward rounds in medicine. RGUHS J Med Sci 3:135-137

21. Vreman J, van Loon LM, van den Biggelaar W, van der Hoeven JG, Lemson J, van den Boogaard M (2020) Contribution of alarm noise to average sound pressure levels in the ICU: An observational cross-sectional study. Intensive Crit Care Nurs 61:102901. https://doi.org/10.1016/j.iccn.2020.102901

22. Zimmer K, Ellermeier W (1997) A German version of Weinstein's noise sensitivity scale. Z Für Lärmbekämpfung 44:107-109

23. Renz T, Leistner P, Liebl A (2018) Auditory distraction by speech: Sound masking with speech-shaped stationary noise outperforms $-5 \mathrm{~dB}$ per octave shaped noise. J Acoust Soc Am. https://doi.org/10.1121/1.5027765

24. Patefield WM (1981) Algorithm AS 159: an efficient method of generating random R $\times C$ tables with given row and column totals. Appl Stat 30:91. https://doi.org/10.2307/2346669

25. RStudio Team (2019) R: a language and environment for statistical computing. R Foundation for Statistical Computing, Vienna

26. Kjellberg A, Ljung R, Hallman D (2008) Recall of words heard in noise. Appl Cogn Psychol 22:1088-1098. https://doi. org/10.1002/acp.1422

27. Lee PJ, Jeon JY (2013) Relating traffic, construction, and ventilation noise to cognitive performances and subjective perceptions. J Acoust Soc Am 134:2765-2772. https://doi.org/10.1121/1.4818776

28. Jansen RS, Lakens D, IJsselsteijn WA, (2017) An integrative review of the cognitive costs and benefits of note-taking. Educ Res Rev 22:223-233. https://doi.org/10.1016/j.edurev.2017.10.001 
29. Wagner-Hartl V, Grossi N, Kallus K (2018) Impact of age and hearing impairment on work performance during long working hours. Int J Environ Res Public Health 15:98. https://doi.org/10.3390/ijerph15010098

30. Grady C (2000) Changes in memory processing with age. Curr Opin Neurobiol 10:224-231. https://doi.org/10.1016/ S0959-4388(00)00073-8

31. Nyberg L, Lövdén M, Riklund K et al (2012) Memory aging and brain maintenance. Trends Cogn Sci 16:292-305. https://doi.org/10.1016/j.tics.2012.04.005

32. Strobach T, Frensch P, Müller H, Schubert T (2012) Age- and practice-related influences on dual-task costs and compensation mechanisms under optimal conditions of dual-task performance. Aging Neuropsychol Cogn 19:222-247. https://doi.org/10.1080/13825585.2011.630973

33. Baltes PB, Baltes MM (1990) Psychological perspectives on successful aging: The model of selective optimization with compensation. Successful aging: Perspectives from the behavioral sciences. Cambridge University Press, New York, pp 1-34

34. Cavuoto MG, Franzese S, Kinsella GJ (2020) Pre-test experience and memory performance in older adults: the impact of test anxiety and self-efficacy. Arch Clin Neuropsychol. https://doi.org/10.1093/arclin/acaa093

35. Tun PA (1998) Fast noisy speech: age differences in processing rapid speech with background noise. Psychol Aging 13(3):424-434. https://doi.org/10.1037//0882-7974.13.3.424

36. Bjork EL, Little JL, Storm BC (2014) Multiple-choice testing as a desirable difficulty in the classroom. J Appl Res Mem Cogn 3:165-170. https://doi.org/10.1016/j.jarmac.2014.03.002

37. Gagnon SA, Wagner AD (2016) Acute stress and episodic memory retrieval: neurobiological mechanisms and behavioral consequences: Acute stress and episodic memory retrieval. Ann NY Acad Sci 1369:55-75. https://doi. org/10.1111/nyas. 12996

38. Park SH, Song HH, Han JH et al (1994) Effect of noise on the detection of rib fractures by residents. Invest Radiol 29:54-58. https://doi.org/10.1097/00004424-199401000-00009

39. Shepherd D, Welch D, Dirks KN, Mathews R (2010) Exploring the relationship between noise sensitivity, annoyance and health-related quality of life in a sample of adults exposed to environmental noise. Int J Environ Res Public Health 7:3579-3594. https://doi.org/10.3390/ijerph7103580

40. Bell L (2010) Monitor alarm fatigue. Am J Crit Care 19:38-38. https://doi.org/10.4037/ajcc2010641

41. Ljungberg JK, Neely G (2007) Cognitive after-effects of vibration and noise exposure and the role of subjective noise sensitivity. J Occup Health 49:111-116. https://doi.org/10.1539/joh.49.111

42. Morrison C, Jones M, Blackwell A, Vuylsteke A (2008) Electronic patient record use during ward rounds: a qualitative study of interaction between medical staff. Crit Care 12:R148. https://doi.org/10.1186/cc7134

43. Thompson VA, Paivio A (1994) Memory for pictures and sounds: Independence of auditory and visual codes. Can J Exp Psychol Can Psychol Expérimentale 48:380-398. https://doi.org/10.1037/1196-1961.48.3.380

44. Kreckler S, Catchpole K, Bottomley M et al (2008) Interruptions during drug rounds: an observational study. Br J Nurs 17:1326-1330. https://doi.org/10.12968/bjon.2008.17.21.31732

\section{Publisher's Note}

Springer Nature remains neutral with regard to jurisdictional claims in published maps and institutional affiliations.

\section{Submit your manuscript to a SpringerOpen ${ }^{\circ}$ journal and benefit from:}

- Convenient online submission

- Rigorous peer review

- Open access: articles freely available online

- High visibility within the field

- Retaining the copyright to your article

Submit your next manuscript at $\boldsymbol{\nabla}$ springeropen.com 